\title{
Constructing Local/Global Pedagogies: Insights into The Learning Experiences of International Students
}

\author{
Michael Singh and Eira Sproats \\ School of Education and Early Childhood Studies \\ University of Western Sydney
}

\section{Introduction}

There is mounting concern that because education policies in Australia are driven by marketoriented neo-liberal globalism that the potential role education can play in a changing national/global environment is being undermined. For instance, Rizvi (2003a) observes that there is a danger that the Australian policies that are moving towards a market-driven higher education, will ignore the debate about the fundamental purposes of education within a global context (Rizvi, 2003a, p. 1).

More specifically, in terms of pedagogy the worry is that efforts to internationalise higher education privilege untheorised claims to facts, rather than pedagogies that engage and enskill students in investigating the historical, ideological and localising practices of the contemporary transitions in globalisation. Pedagogically, Rizvi (2003b) suggests that the internationalisation would benefit from "a curriculum approach that seeks to provide students with skills of inquiry and analysis rather than a set of facts about globalisation."(Rizvi, 2003b p. 4)

This paper explores the possibilities for developing inquiry-oriented, analytically enskilling global/local pedagogies by examining evidence of the formal and informal learning experiences of international students from the People's Republic of China who studied at Australian universities. It presents a summary overview of data from interviews with some 120 international students, along with a series of pen pictures of selected students' perspectives. The paper begins by exploring their initial formal and informal education in China for factors that informed the students' desires to study overseas, indicating how this contributed to their readiness for continuing their studies in Australia. Second, consideration is given to both the formal and informal learnings the students experience in Australia in terms of how these deepen and extend their trans-national education begun in China. Third, their views on the gains and disappointments of their educational experiences in Australian universities are examined. Finally, we consider some global/local pedagogies that might be possible given the constraints market-oriented neo-liberal globalism now imposes on universities.

\section{Informing Students Desires to Study Overseas}

All the students had formed a strong desire to study overseas while in China. A range of factors contributed to their readiness for an international education. Some of them were influenced by family, including mother, father and grandfather, but a few from those who were working or had done some graduate work in China, made the decision themselves. Many of those who were interviewed had family members who been overseas, and so had some idea of what it would be like. There was also a culture among the more well to do of sending your children overseas to study, it was fashionable.

There were however many other factors that readied these students, making them international students before leaving China. Some received scholarships which made it much easier for them to go. Many of the international companies in China want highly qualified personnel with overseas qualifications. This will secure your future which is a very desirable thing in China.

There were also students who said they wanted to improve their English and saw going overseas to study as a way to do that. Some wanted to learn things about the outside world and have their minds and eyes opened. One of the reasons for choosing Australia for overseas study was the availability of the Permanent Residency here. 
Wang Ming was a young man who came to Australia from Beijing, at the beginning of year 11 High School, and studied for 2 years at a high school in Melbourne. He said:

Because I want to study at a University in Australia so I think it is an easy way to get into a high school and pass the VEC and enter university.

He gained entry into the university of his choice to study a double degree, Commerce and Information Systems. His father was a freelance journalist who had worked in many countries and had lived in Australia for a year. Despite this seeming influence, Wang Ming said he was allowed much freedom of choice by his parents. He decided he wanted to study in Australia because he would have more choice of subjects at high school and he could choose subjects that would help him with his career. He said about his high school education in China:

You can't make any important decisions because the subjects are appointed by the department of education. You can't choose many subjects.

He also wanted to experience the culture of Australia and try learning something different than what he learnt in China. One of his major concerns was to be able to improve his English. He had learnt some English in China:

In primary school just some letters and simple words. In secondary school a textbook and they just teach you and ask you to study some works some grammar and not too much speaking.

The family had considered overseas education because "Western education is better for my future," said Wang Ming. Wang Ming decided himself he would like to come here. His grandfather also thought "some overseas experience is good for you." Wang Ming's friends also said it was a good idea:

They think I have more opportunities to have a better future because in China most people appreciate overseas education, because some people think Western education is more advanced.

Were Wang Ming's aspirations fulfilled? It would seem so. He said later when asked if it was helpful:

Yes because they tell you it is better for your personality and study and learn how to study by yourself and I think the content of the courses will be of use, because also China has become a member of WTO and they need many people of international knowledge.

For students like Wang Ming it is reasonable to say that the evocation of cosmopolitan desires for mobility and their families already established "reciprocal interconnectedness" (Brennan, 1997, p. 16) led to their international education at home and abroad. These desires were mediated by the rise of English as the worldwide lingua franca, as much as other forms of global connectedness created by the local/global flows of people and media. These students consciously preferred to study abroad in English which they accepted as "an enlightened linguistic imperialism" (Brennan, 1997, p. 144) necessary for in/forming the trajectory of their life project. Studying overseas is also an expression of and response to a renewed Chinese cosmopolitanism initiated in the late 1970s under Deng Xiaoping's policy of socialism/capitalism with Chinese characteristics and celebrated in 2001 with China's entry in the World Trade Organisation. Because university 
education is no longer limited to its imagined place of "origin" in and for a given nation-state, it might be freed from the prejudices of provincial or parochial pedagogies. An international education now belongs to the "sophisticated, urbane, worldly" (Brennan, 1997, p. 19), where studying abroad is integral to structuring of students' life projects, especially their future career trajectory.

\section{Formal and Informal Learning Experiences in Australia}

Now we turn to a consideration of how the students' formal and informal learning experiences in Australia deepened and extended their trans-national education begun in China. We also wanted to know how they planned to use this learning.

The students learning experience in Australia was both formal and informal. Yang Hui summed it up this way:

... studying in Australia is not a program of study it is a program of how to live and how to find work and very big pressure.

\section{Informal}

The students informal learning experiences which were gained through part timework, living, friendships and cultural engagements, impacted on their character and prepared them for work when they returned to China. They commented on being more independent, more mature, coping better, handling difficulties, being more confident, and learning to live with other people of my age. They all felt that these things would help them when they returned to China.

Another common topic was learning about the culture of another country. The importance of cultural hybridity in local/global pedagogies is referred to in terms of developing a "culturally sensitive curriculum" (Rizvi 2003a, p. 6) and "intercultural interactions and exchanges" (Power, 2000, p. 153). It is important that the cultural exchange goes both ways. Too often these international students did not have opportunity to express their views. These students said that before they came, parents had said they would learn much from another culture and although it was hard to learn about the Australian multi culture they expressed the views that this experience of life was most valuable. One student learnt from the way Australian people treated each other, with respect and sharing ideas. Wang Ming said :

Yes because I knew people from different cultures and countries and this has benefited me. It has helped me interact with non-Chinese people- because in China we do not have many opportunities to interact with people from other countries.

Most of the students had part time jobs while they were studying. Through this they learnt communication skills and how to work in the Australian environment.

\section{Formal}

As many students pointed out, the educational system of China and Australia are very different. While they learnt new skills through their Australian education (Power, 2000), a continuing difficulty was that "Western educators still lack the understanding of Chinese students mode of learning" (Wong 2004, p 154). However, the students were enthusiastic about what they had learnt through their formal education. These learnings included: how to solve problems; how to work in groups; how to refer to books; and how to communicate through making presentations to groups in tutorials.

Many of the students commented on how they would use this learning. They felt that their formal learning would help them to get a good job in China. Their exposure to a foreign multi culture meant that they are very attractive to international companies also 
... my education prepared me well for good job with language, culture, knowledge, if I got a job here the firm can send me back to China. (Zhang Yi)

While in Australia the students learned that globalisation includes the local/national/global flows of people, expressed most clearly in the multicultural demographics of Australian society. Much was learnt from Australian companies, Wu Jun thought they worked more efficiently than Chinese:

Here is more like teamwork. You discuss things together and then you do the task. But over here it is like a hierarchy so lower level of staff always follow the supervisor and do at they are told.

\section{Wu Jun's Story}

$\mathrm{Wu}$ Jun went on to do a Master of Professional Accounting after completing a Bachelor of Transportation Logistics. She came from a province in the Eastern part of China near Shanghai. Her father owns a property development company and he wants her to go back to China to work in the company. Wu Jun does not want to do this at the moment. Her father also helped her make the decision to come to Australia, tohelp with her English and for networking opportunities later.

Wu Jun's formal education in Australia was firstly Bachelor of Transportation Logistics. After finishing this degree she found it very hard to find a job here and she knew that a bachelor degree would not be enough for a job in China. So she did her Masters of Accounting. She said:

The reason I chose accounting is because actually my father really hope I can help him in his business. So I think when you are doing accounting you will know every detail of the companies operation so maybe it is better.

She learnt much from her lecturers:

They are good teachers, they are always responsible for you and if you have difficulties they will always come to you and help you.

She particularly liked the personal examples:

they read the book and put their own experiences so that is good but we would like to listen to more of their experiences. We have to read the book to pass the exams.

Informal learning took place through jobs, learning the culture of the country, through friendships leading to networking, through everyday living even the more informal nature of her university education. When talking about her accounting degree $\mathrm{Wu}$ Jun mentioned about having fun while learning, even accountants should be exposed to music art and plays.

She talked about the informal learning of having a job:

It would be very good if during you studies you had some practical stuff as well as theory. I find that work placement is totally different to what you learn from a book. My manager taught me how to put in a staple, I learnt from the work place.

When she first arrived Wu Jun did not need to work, her father was able to support her and told her not to work. But after she had finished her undergraduate degree she felt she needed to work. She needed the experience and she felt she was being lazy. She was happy to do cleaning motel rooms( the only job she could find) although she did not tell her family because if her father knew he would be really angry. 
One of the things she learnt here which she liked very much was living for herself and not for others, especially in her job. She liked the idea that here it did not matter greatly what clothes you wear or what sort of car you drive people just accepted you as you are. She also learnt to be independent, although sometimes it was a struggle. During enrolment at the university, she discovered that even though she didn't like it, if no one guides you, you actually learn more than if it is all done for you. One of the major advantages for $\mathrm{Wu}$ Jun was when she joined the International Students Association. Because of her accounting she took on the job of treasurer and found it was very useful for her later on as it gave her some experience which was needed for jobs. She said:

For me I feel very confident for my future because I have my work experience for 1 year and my social activities because I am treasurer of the organization and I learn much from work because my company is a Chinese company.

She also thought it would be good to join the association for networking. She met other people and made friends there because she found it easier to communicate with students from Asian countries. Unlike China where education seems to be focused entirely on getting to university and getting a good job and making money and having a good future $\mathrm{Wu}$ Jun learned from staying with an Australian family that education is more than that. She found they really cared about how to enjoy life and making money came second. Wu Jun has changed significantly, learning from all the experiences she had here and she has become more confident, she is now more mature, and her thinking is very broad.

The students found pleasure in their informal education because of its lack of closure. These were a model of versatility and virtuosity. Students had the opportunity to play expressively and concretely with the English language. This was in preference to a closed, blunt and finite lecture. The students were motivated by this complexity and their respect for attributes like "care, circumspection, humility, perceptiveness, and sensitivity" (Brennan, 1997, p. 72). However, that the students' report that they mainly network with other Asian students, may suggest that cultural hybridity is central to understanding the internationalisation of Australian education. The ethnic other continues to be a cultural-historical stimulant to educational innovation. In Australia, the increasing presence of non-European people since the mid-1970s is shaping changes in the educational imagination, connections and regulatory forces. Market-oriented policy, pedagogical and political initiatives in internationalising Australian education have overestimated the promise that it has made, although the seductions of Australian multi culture make this easier. Very few students encountered discrimination or racism. Language and culture were represented as the barriers to being able to form deep relationships with local Anglo-Australians students, and not the failure of universities to develop investigative pedagogies that took local and international students together as the media of contemporary globalisation. The divide between local and international students from Asia echoes the era of White Australia politics. It is as if the neo-conservative governance of Australia/Asia relations which has involved manufacturing fears and managing crises around asylum seekers, Arabs, Moslems and Indonesians has that put limits on local/global pedagogies that engage and enskill local and international students in the collaborative production of knowledge. However, students' concerns about English language proficiency and employment to offset the costs of education shaped their formal and informal experiences of education in Australia.

\section{The Gains and Disappointments of an Overseas Education}

In this section we turn our attention to the question of what the students saw as the gains and disappointments of their overseas educational experiences. Students should be learning things from an international perspective and learning to be more open minded and think critically (Leask, 2003, p. 1). 


\section{Gains}

All of the students commented on some gains from their overseas educational experience. They included improving their English, which in turn will enable them to get a better job in the globalised economy. Many of the students talked about other skills they had learned which will help them later when they return to China. These included basic computer skills, life skills, how a company works, as well as communication and social skills. Almost all the students said that the courses that they did plus their other experiences prepared them well for work especially in China. Wu Jun said a combination of her course, work experience and social experiences would help her get a job

One of the best ways to be sure of a job was to obtain a Permanent Residency Visa. The PR was also useful for migrating and for travelling abroad. Some students felt that they had learnt a lot about Australian culture while they were here and this was good:

I have learnt from multiculturalism, I have learnt much for my future. This society is more open- minded and flexible. (Yu Lei)

The whole experience of overseas education had a great impact on the students' personal lives. Most of them spoke about becoming more independent, being more mature, more confident, and being more open minded. Many of these things were learnt from having to live and work here independently of their parents. They learnt a lot from the western education system. It was very different to the Chinese way, and they discovered the good from both systems. Some of the good things they learnt about the western system were that it was more flexible, there was more choice, more opportunity to create, critical thinking, more practical, more discussion

over there you only have you ears in class but here you have your ears and your mouth. It is more participatory. (Wu Jun)

There is more communication between the students and the teacher here even being able to argue a point. One student said he now knew more about Chinese culture because the world was getting smaller. Xiao Lu said that

... students will bring home to China the idea that all people are the same because we have experienced it here.

\section{Disappointments}

The down side of the Australian educational experience was that there were not enough Australian students in the classes for them to learn from. They had trouble interacting and integrating with the Anglo Australians because of the difference in their culture and the language barrier. Yu Lei said:

I cannot accept the Australian culture, rugby, volleyball and football -not for me I don't understand them.

Although the Anglo-Australians were very friendly and helpful it was hard to get to know them well and make close friends of them. Consequently most of the students friends were Asians, especially Chinese.

Some of the students also felt that they were not cared for enough by the University when they first arrived in the country. They also felt that the Universities were using them as a way of making money.

They don't look after the students very well and the quality of the program is not good.

They are more interested in the money. (Li Yan) 
There was an International Students Association at the Universities but many of the students didn't seem to know about it or use it. There was not enough good communication with the students. Just three of the students commented on their courses not being good and that they didn't really learn much from them. There did seem to be some problems too with the availability of jobs in China now. Things were changing, companies were not so eager to employ overseas people, local students were cheaper. Some of the students spoke about the differences of the two systems of education. One student expressed the differences like this:

Australia develops a student's identity. In China the teacher always, we call it duck feeding. In one way it is good the basic education is very good in China, secondary education is very good but later on, when we enter into University, we should become more independent, do some research for ourselves, we depend on the teacher too much.(Shan Hua)

The students had such high aspirations for their education here in Australia. However a few of them were a little disillusioned.

\section{Shan Hua's story}

Shan Hua comes from a small city in China. Her two younger brothers studied in Australia and she followed them here to do her education degree and then returned to China to teach for one year. She then returned to finish the Diploma of Education in a Melbourne University. One of the reasons she came to Australia was that she was she wanted to find out more about it the education system here For Shan Hua there was much that she gained from her overseas experience, not only from her formal learning. Shan Hua also spoke about the influence of the multicultural society and the variety of things in Australia. She said:

Because Australia is a multicultural country we can learn different culture and share ideas. From people of different background in China we can't.

She also said her English had improved a lot. She soon realised that the system of teaching English in China did not give them enough opportunity for speaking and listening which she was now getting. Shan Hua was able to get Permanent Residency and this helped her to find a job in Australia teaching at a local high school. She also spoke about the practical help she received when applying for jobs:

I finished my resume and send to the career centre at the university, the teacher there helped me gave me some advice. ... For the interview very useful advice I must not to use the Chinese way. I must not be humble you can even say you are the best. ... Then they asked me some questions I answered them and they said oh these answers are not very good, you need to say this. Very practical.

There were also many other skills that Shan Hua learnt while she was here. Many of these she said would be very useful for her to use when she went back to China:

I think I learn something and I should bring that knowledge back to China. China needs a lot of I think need us to help the country. Improve the education systems. I am proud that I am Chinese I think that that is my responsibility.

She picked up skills from her part time job, her university course interacting with other students, from living in the culture among so many different people: 
When I worked as a waitress I have opportunity to talk with different kind of people in restaurant western people Chinese, Asian, Japanese, Korean it is a good way. Help your communication skills.

The many friends she made here would be a great source of help when she went back. She had made friends with Australian and Asians and so had a network of people from different backgrounds that she could call on. There was much about the Australian teaching style that Shan Hua liked. Although there were good things in the Chinese system she liked that Australia emphasised communication and social skills. They taught the students to be more independent doing much more of their own research. It was a hard process for Shan Hua to adapt to the Australian way of learning. It went against her 'Chineseness', but she found it was a very good experience and helped to develop her as a person:

In the classroom, at first I think oh this is very hard, hard for me to fit into the new education system because Asians are very shy from the culture aspect we can't say I'm very good I'm the best we must think OK I'm good I need to learn more. But later on during my study I open my mind and share ideas with the other students and learn a lot I think those kind of social skills are more important.

She found she learnt a lot from the teachers too for her own career:

They are very professional, they not only have academic knowledge, they are also very kind they can understand students from different background and culture.

There were many personal changes in Shan Hua too. She was more mature, more independent (she had learnt to cook and look after herself and her brothers) and has improved her communication skills. She said she was more open, not quite as traditional, "and can appreciate a lot of things different culture and customs." She was happy with the way she had changed and developed.

Although Shan Hua learnt many good things from the culture of Australia especially the multicultural nature of society she was also disappointed in some of the things that she saw, where she preferred Chinese culture and tradition:

Chinese people they always think about others. We have a tradition to look after kids and respect older people and be considerate.

There was also the constant difficulty with the language. It is not just the English language that needs to be understood, but often the way things are done here and even the educational policy. She also felt that most of her courses were not relevant to China.

One of the big disappointments for Shan Hua was that there was not a lot of interaction with Anglo Australian students. She had hoped to be able to meet lots of students and really get to know them. However the language and culture proved to be very big barrier to many close relationships although she had many Anglo Australian friends.

The reason for this she said was:

The way of thinking. The interest is different, sometimes I find it is difficult to have a deep conversation with western people because we have different interests.

When Shan Hua first came here all she wanted to do was to improve her English and go back to China to teach. She was very surprised that so many other changes took place. She unexpectedly obtained a teaching job and really loves that and feels that she can be like a bridge teaching some Australian about Chines language and Culture. 
Where Chinese identity appears as a more restricted set of personal choices, fulfilments and self-consciousness, it undermines recognition of its social formation at home and abroad (Brennan, 1997, p. 113). The effort to understand cultural hybridity is not merely a matter of historical boning up, the learning of terms and figures or even of foreign or global languages. Each of these things is important. However, it is not merely an accretive process, but a liminal one. The students' cosmopolitanism is neither a matter of being a worldly traveller or being post-national. It is related to ideas about the possible reconstitution of the Chinese nation-state, transculturation (rather than assimilation), cultural hybridity and the questionable view that consumption is an exciting, viable form of national/global politics.

Thinking of China in terms of a 'third world' country represents a "deadening, insufferable homogenisation" (Brennan, 1997, p. 61) that is removed from complex realities of today's China. All of its differences congeal in the inexorable conversion of China into an area to be dominated as offering markets for Australian higher education and suppliers of students - raw materials - for processing. As noted below, students point to the high-handed manoeuvrings of Australian universities. Is active colonialism now manifested in the form of transnational university corporatism, with Australian universities securing their interests and profits globally. The yielding of nation-building university education to international trade is made on the promise the worldwide triumph of Australian universities as trading companies. These students battled between feelings of disappointment and ambition, although these did not present themselves as polar opposites. The negative treatment as customers reported by students also indicated their refusal to be victims.

\section{Possible Global/Local Pedagogies}

What global/local pedagogies might be possible given the constraints on universities? Many things have been suggested as important for global pedagogy by a number of people. These include; recognising international students as a resource, using international examples in the curriculum, recognising the problems that international students face with English, different teaching/learning strategies, being sensitive to context and culture. (Hamnet, 2003; Curro and McTaggart 2003; Gao 1998; Curtin University, 2003)

While it is important and highly desirable that university pedagogies are local to suit the needs of the local students, it is also very important that they have a global perspective as well. Universities are more and more becoming Global and Internationalised and so it is important to know what they should be teaching to the international students who are coming to their campuses. Globalisation has a great deal to do with learning from other cultures. Many of the students commented on the multicultural aspect of their experience in Australia and how much they learnt from that.

What is the reality of the situation in Australian universities? Do we have parochial localism or global localism. Does our pedagogy produce " graduate students who can think critically and have a deep understanding of ideas, developing students who produce knowledge by drawing on resources from different fields and integrating these with their own experiential knowledge so as to speak to their real life contexts" (Singh, Kenway and Apple, in press/2005, p. 6). Are we encouraging International Students to share their knowledge and experiences with the other students. We will discuss the constraints and the possibilities of having more global localism in our pedagogy.

\section{Constraints}

There were some reasons that the students gave for feeling that Australian pedagogy was too parochial. One was the nature of the make up of the classes and this meant that the students had trouble learning from the Australian students. Sometimes the students felt left out and not able to relate to the others in the class. They said the Australian students, and sometimes the lecturers, ignored them. 
But generally speaking I truly enjoy the teaching style here but they tend to ignore us because there only about two or three Asian students in a 50 student class so they treat us like Australian students and that is very difficult. (Shan Hua)

Xiao Lu felt it was hard to learn from the others in her class because of their differences,

and it is hard to share experiences with them because their lives are different there is nothing in common expect speaking English but they are not real interested.

There were however some good points. When they were forced into groups for an assignment they felt that they learned much from the other students

Yes we do group work and not only the tiny group here together but also a group from other countries. Yes I have got to know other people from other countries, we learn about each other and learn each other's cultural background (Yang Hui).

Another constraint was inappropriate courses where students felt there was not enough input of things outside Australia. They struggled with having just Australian content and no opportunity to discuss what happens in their own country:

Management assignment what is the manager's role in the organization. It is possible to gear it to China it would be interesting but I haven't tried to do that. I haven't been encouraged to do that by my lecturers ......(Wang Ming).

Zhang Yi spoke about the Australians learning from the international students:

... because the way we are thinking and the way they think is different, so we learn from each other............... think the Australians are benefiting but they don't really take advantage of this, they still keep to themselves.

One of the major constraints for the students was the difference between the teaching strategies of China and Australia. Firstly because the teaching was in English the students had many problems especially at the beginning. Some felt the lecturers did not make much effort to help them to understand. One of the biggest complaints was that they spoke too quickly. They had problems with such things as having to make a presentation to the class:

Sometimes I have ideas about what to say but I have problems expressing them (Zhang Yi).

Other problems were the fact that in China research focuses on the outcomes whereas in Australia it focuses on the process. Another problem was the writing style including grammar and sentences and the writing of essays and comprehension skills. Paraphrasing and referencing; and assessment tools were very different.

Some of the problems they mentioned were because in China they did not do these things because of lack of money and because there was overcrowding. These are methods of study they have to adapt to and learn here. Despite all this it has to be remembered that many of the students came to Australia to learn about other cultures and the way other people live. They wanted to practice their English and learn something about the education system here. One said that he came to this country to learn about the culture and information about this country and did not really want to learn about China he already knew about that. 


\section{Possibilities}

What did the students see as good pedagogies? What are things that universities can do.? The idea that Chinese students learn differently and cannot change is not valid (Hellsten and Prescott, 2004, p. 344). Many of these students recognised the difference in their own education and commented on the good things about it but also said they liked many things about the Australian system as well. Wong (2004, p. 154) said " My personal experience has led me to believe that one can be flexible in one's learning practices." However it is recognised that" there can be a serious mismatch between learning styles of students and the teaching [strategy] of the instructor" (Zhenhui, 2001, p. 1). Universities need to take note of the things that the students said about their learning experiences here. Many of the students spoke about learning from each other and from the culture that they saw in Australia.

They spoke about good things from Chinese pedagogy and good things from Australian pedagogy and some spoke about trying to combine the best of the two systems. They spoke about the difference in the way the University looked after them. They felt they met a lot more people in the Chinese university because they often were provided with accommodation there and they were at the university for longer during the day and interacted more with their fellow students. Quite a few said that the teachers in China were very helpful, a very good teacher student relationship, although this sometimes turned into 'do the work for you' or 'spoon feed you'

In China the teacher will make every point for you, you don't need to spend time by yourself, he will explain everything (Lui Yang).

Students felt that the education in China was good for maths and science, because the normal method of learning was through memorization, that it was superior to Australia in this area. Many of them spoke about the Chinese education system of working really hard to get into University and then passing University and getting a good job. The things the students liked about the Australian system was that it taught them independence, creativity, was more practical and hands on, gave them more choices, more motivation, more freedom, and they learnt a lot from the culture of the country and meeting and studying with students from other parts of the world. One student spoke about trying to mix to two systems together taking the best from each:

Sometimes we don't give the student much freedom, but in another way it is pretty good because kids are not as mature as adults they need our direction. ... We should balance Chinese way and Australian way Shan Hua).

There were already lecturers who referred to things outside Australia particularly in China, and thus some of the students felt that the Universities were already teaching an Internationalised Curriculum:

One of the major benefits is to learn about other countries which I would not have done if I had stayed in China and gone to University there (Yu Lei).

He claimed that in China they did not keep in touch with the national/global economy. But there were also many who felt that only Australian content was in the courses they did. One suggestion from a student was:

I think it needs to be more international more information from the different countries education system (Shan Hua).

The students appreciated good global pedagogy because it led to them getting good jobs in China. However one or two had found that this was not as easy as it use to be. Some said if you have a post graduate degree and overseas experience you will get a good job with an international 
company. But there was the warning that this is not always the case now. One of the good things the students saw was learning from people from other cultures often by sharing group work or small tutorial groups. They felt this made their course international and global:

My knowledge of my teaching in China was used in some courses. In class in the group we share ideas, what it is the difference between Australia and Chinese way of thinking their education practice their teaching methodology (Shan Hua).

When asked this question, "Do you think coming to Australia has made you a more globally orientated and international kind of person?" Wang Ming replied

Yes because I know people from different cultures and countries and this has been a benefit to me. It has helped me to interact with non Chinese people because in China we have not many opportunities to interact with people from other countries.

There can be no consideration of national education without reflecting on contemporary transitions in practices of globalisation. There can be no talk about the globalisation of Australian universities without consideration of the tensions in their Americanization and Asianisation (Brennan, 1997, p. 125). Americanization means the massification of the global sphere by marketing its technologies, information and communications. Australian universities are highly organized cultural apparatus for effecting this dissemination. They employ an immense array of personnel and strategies which facilitate the internationalisation of the education from within China. The employment of these technologies is made possible by the rise of the information classes, the transnationally mobile knowledge workers. The massification of Australian university education was part of the irrepressible march toward the internationalisation of its education. Australian universities have a semantically rich epiphenomena-their various narratives in the forms of actual programs, printed materials, and celluloid fantasies. There is a debate over whether universities should now be structured on a 'national' and 'global' basis. Those responsible for tailoring university structures struggle with these new possibilities.

In spite of the title "university" and its connotations of being unprovincial and nonidiosyncratic, their efforts to internationalise the curriculum may be seen as an admission of "global parochialism" (Brennan, 1997, p. 158). Australian universities need to work towards being more globally localised. This can be helped by taking the best of both forms of education and using the good things that the students have spoken of from their Australian experience. It would be good to note also the complaints the students made and try and improve on things where practicable and possible. One pedagogical move strategy is to link what local and international students remember having studied at school with the study of globalisation as the mass movements of people and knowledge, where the latter is investigated as an expression of the former. This means identifying the motor of innovation in higher education not in technology, or the demands of transnational capital or the political and ideological projects of neo-liberal and neo-conservative globalisms, but in the character of Chinese and Australian societies. Education, like politics is "concentrated economics" and gives direction to the politics of innovative activities (Brennan, 1997, p.238).

\section{Conclusion}

What might now be said about constructing local/global pedagogies from critical insights into learning experience of international students? The students came here with high expectations. They wanted to improve their English; they felt an overseas education would be better for their career prospects; they felt the cultural exposure would be good for them, and they were of the view that western education is better than that currently available throughout China.

Some of important points from these students' experiences that enable us to rethink local/global pedagogies are worth noting here. First, concerns about students' proficiency in the 
English language, especially writing skills should not be mistaken as signifying any lack of intelligence, motivation and engagement. The differences in learning/teaching strategies between Australia and countries such as China invite consideration of how educationally sound aspects from each might inform local/global pedagogies. There is a need to recognise the international students as a resource or a medium through which the processes of globalisation/localisation might be investigated. Pedagogically, if universities want local students to understand and share other people's culture in order to position them in the transnational labour market then we have yet to develop local/global pedagogies that bring students together to learn from and through each other. In recognising the importance of informal as well as formal learning, there arises the question of how the former dimension of their overseas education might be subjected to critical reflection through a process of documentation and thereby formally accredited as part of their studies. This would give a new and no doubt challenging dimension, perhaps a point of difference in the market, to incorporating local/global pedagogies in university curriculum and teaching.

\section{References}

Brennan,T.(1997) At Home in the World- Cosmopolitan Now. Harvard University Press. Cambridge, Massachusetts.

Curro, G. and McTaggart, R. (2003), Supporting the pedagogy of internationalisation. (A paper presented at the $17^{\text {th }}$ IDP Australian International Education Conference, Melbourne, Australia).

Curtin University (2003), Internationalising the Curriculum. Learning Support Network: Perth, Western Australia.

Gao, M. (1998) Influence of native culture and language on intercultural communication: The case of PRC student immigrants in Australia. (A paper presented at a symposium on Intercultural Communication at the Department of Linguistics, Gothenburg University, Sweden).

Hamnet, A. (2003) Globalisation and internationalisation in higher education in the twenty first century: Internationalising the curriculum. Curtin University Learning Support Network: Perth, Western Australia

Hellsten, M. and Prescott, A. (2004) Learning at University: The International Student Experience. International Education Journal, 5 (3),(pp344-351)

Leask, B. (2003), Beyond the numbers: Levels and layers of internationalisation to utilise and support growth and diversity. (A paper presented at the $17^{\text {th }}$ IDP Australian International Education Conference Melbourne, Australia).

Power, C. (2000), Global trends in education. International Education Journal. 1(3), pp.152-163.

Rizvi,F.(2003a) Identities "On the Move": Student Mobility and the used of International Education. (Unpublished paper, University of Illinois, Urbana-Champaign.).

Rizvi, F. (2003b), Internationalisation of the Curriculum. RMIT University Melbourne Australia

Singh,M. (2005), Enabling transnational learning communities: Policies, pedagogies and politics of educational power. In P.Ninnes and M. Hellsten (Eds) Internationalising Higher Education: Critical Explorations in Pedagogy and Policy. Hong Kong: Kluwer.

Singh, M., Kenway, J. and Apple, M. (in press/2005), Globalising education: Perspectives from above and below. In M. Apple, J. Kenway and M. Singh (Eds.), Globalising Education: Policies, Pedagogies and Politics. New York: Peter Lang

Wong, J. (2004), Are the Learning Styles of Asian International Students Culturally or Contextually Based? International Education Journal, 4 (4), 154-166

Zhenhui, R. (2001). Matching Teaching Styles with Learning Styles in East Asian Countries. The Internet TESL Journal, 7 (7), 1-9

Paper presented at the 2004 ANZCIES conference, Melbourne, 3-5 December. 